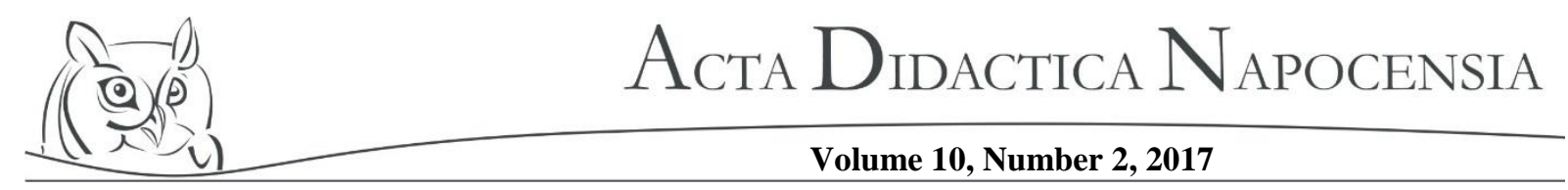

\title{
THE BELONGING TO THE UNIVERSITY SCALE
}

\author{
Omer Karaman, Yuksel Cirak
}

\begin{abstract}
The aim of the study is to develop a belonging to the university scale (BUS) in order to determine the level of fulfillment of the need to belong among university students at the higher education institutions they attend. The population of the investigation includes university students studying at the campus of Ordu University. A 5 point Likert-type scale was created in the study. The SPSS 15 and LISREL-8.15 programs were used in the statistical analysis performed during development of the scale. Content validity and construct validity techniques were used for validity analysis. The internal consistency checks of belonging to the university scale were completed. The research data is given as mean and percent, and t-test and one-way variance analysis were conducted in order to determine the differences between the groups and the values of belonging to the university. The internal consistency Cronbach $\alpha$ reliability coefficient values of the scale and the test-retest reliability of the test results were satisfactory. Exploratory and confirmatory factor analyses were performed for the construct validity of the scale and three dimensions (Motivation, Expectations and Identification) were identified. The level of belonging of university students to the university they attend was examined with the scale with the validity and reliability tested and suggestions are presented in accordance with the obtained results.
\end{abstract}

Key words: The Belonging to the University Scale, University Students, Expectations, Motivation, Identification.

\section{Introduction}

University students are faced with a "distressed" but "necessary" life, in addition to the problems of adapting to a new environment, making new friends, making decisions for themselves and meeting their requirements. One of the environmental (culture, building, class population, etc.) and personal (assertiveness, intelligence, ability, etc.) factors that supports achievement of planned educational goals and happiness of the student who spends a large part of his life at school is the need to belong.

Every human being is born with the need to belong. Belonging expresses itself in the form of being together, sharing, solidarity, serving, friendships, establishing friendships, building families, participating in groups and associations; in short, it is the social aspect of the person. Every human has these requirements [1]. Adler [2] stated that in the case of not meeting-the belonging requirement, people have problems in communicating with their environment and difficulties in accepting themselves with feelings of inferiority and inadequacy. Glasser [3] suggested that the feelings of love and belonging play an essential role in satisfying other requirements as they are the most basic requirements. Keenan [4] has emphasized that people's feeling that they belong to a place and have social status is a more powerful factor of motivation than the satisfaction of physiological needs. Maslow mentioned the state of belonging in the third stage of the needs hierarchy theory. According to Maslow, individuals who grow up in an environment where they do not meet their essential requirements, such as security, loving-being loved, and belonging to a group, will have difficulty in finding opportunities to achieve status or the belonging requirement [5].

If the belonging and respect needs of the individual aren't met after his physiological and safety requirements have been met, resentment and anger will arise and these types of emotions may trigger 
violent behavior. In addition, individuals may feel different to others and consequently ethnic pathology may arise [6]. Also, when belonging needs aren't satisfied, it may lead to the emotions of failure, social isolation, alienation and loneliness [7]. Additionally, many negative behavioral, psychological and social consequences such as mental illness, a tendency toward crime and social isolation have been described in relation to the lack of the sense of belonging [8]. Aypay et al. [9] according to the report of Christe and Dunham, higher education is not only a process in which the students earn academic and professional qualifications, but it is a process through which students gain and develop non-academic and nonprofessional significant skills such as social communication skills and social life skills. In this regard, the university must prepare all areas of the educational environment in order to obtain returns from their efforts to meet the student's belonging and other basic needs.

The purpose of the study is to develop a valid, reliable and useful "Belonging to the University Scale" for determining the satisfaction level of the belonging requirements of university students at the higher education institutions they attend.

In recent years, problems related to the creation of a desired school climate have arisen in both our country and in the world. Many problems like violence, drug use, absenteeism, and failure in schools have directed the state to solve the problems with large-scale projects. However, there is difficulty in finding permanent solutions.

Creation of a school culture and actions and motivation of all units in schools together with students to achieve the determined educational goals is dependent on several factors. One of the main topics of the development process of this multi factorial process is the students' personal development and happiness. Therefore, fulfillment of the psychological needs of students by the school is important. According to Ma's [10] report, Routh has stated that the attention of the school to the socioeconomic and academic improvement of students and students' awareness that their teachers are attentive, courteous, helpful and compassionate strengthens their sense of belonging to the school and supports their sense of academic responsibility.

Dana et al [11] according to the report of Crandal, students who feel their belonging requirements are met develop a sense of value and self-confidence. In fact, Pittman and Richmond [12] analyzed the relationship between the feeling of belonging to the university, the quality of friendships and psychological adjustment of freshman college students in the process of transition to college. The research findings showed that the feeling of belonging to the university and the quality of peer relations are the most important factors in the adaptation process to university. Positive behavior, high motivation, selfesteem, self-efficacy and competence are seen in students who have their belonging requirements fulfilled [13]. Similarly, Ma's [10] report, Kum-Walks have attributed the recently escalating violence in schools to the inability to meet the belonging to school need requirements of the students. Again, Walter et al. [14] according to the report of Beck indicated that discipline problems in students usually occur because of the lack of a sense of belonging; and ensuring the participation of the students in social relationships and social activities may be useful to meet belonging requirements of the students. Walter et al. [14] emphasized that the failure to meet the belonging needs of the students may also cause shyness as well as unwanted behaviors. Gilligan [15] associated the violence in schools and academic performance with the lack of fulfillment of the belonging to school requirement.-In another study related to academic performance, Roeser and Midgley [16] and Osterman [17] found a significant relationship between academic achievement and belonging. Also, Roeser and Midgley [16] suggested that the communication between teachers and students is associated with this relationship. In another study conducted on the relationship between academic performance and belonging, Lambert's [18], report Freman et al has demonstrated that there is a direct relationship between belonging to the university and class, being noticed, feeling accepted and academic motivation Similarly, Finn [19] suggested that dropping out will increase in schools where belonging needs are not met. He also stated that the lack of a sense of belonging will lead to alienation and academic failure [10]. According to Furrer and Skinner [20], Dreikurs and Cassel have shown that students feel loneliness, anxiety, frustration and sadness in the educational environment if their belonging needs are not met. However, they manifest high levels of happiness, excitement, and interest in learning activities, if their belonging needs are met.

Anderman [21] has done extensive research on the effect of the school on the psychological status of adolescents and indicated that belonging is also an important factor among various factors affecting the 
configuration of personality. By means of this research, we will be able to determine the belonging levels of students and will be able to develop a strategic treatment approach in problematic cases. In studies on the achievement of goals set by the Higher Education Council and student satisfaction with acceptance, the ability to identify general levels of feeling of belonging to a school among general descriptive factors, will allow access to significant data during project development. Additionally, generally situations which prevent belonging to school requirements being fulfilled can be detected and then efforts to resolve the problems can be made within the framework of preventive counseling and guidance services. Response of higher educational institutions to the expectations of the students at a minimum level is very important in terms of institutional continuity and competition with other similar institutions. Therefore, creation of policies for belonging needs together with other factors among student expectations is a modern management practice in higher education institutions. But data collection tools are needed in order to determine the belonging needs and accordingly to steer all the components of the higher education system in this direction. However, a measuring tool to determine the needs of the students in this area was not been found in the relevant literature.

\section{Method}

\subsection{Study Population}

University students studying at the campus of Ordu University comprise the population of the investigation.

\subsection{Sample}

In this study, the final form of the scale was applied to three sample groups and the retest technique was used in the development process. A literature review for the scale was conducted and potential items related to the subject were obtained. In the research, the sample group used in the development of scale was called "sample-1", the sample group used in the test retest was called "sample-2" and the sample group analyzed in terms of a variety of variables and to which the final form of the scale was applied was called "sample-3".

\section{Sample 1: Trial Form of the Scale}

In the first phase of the study, the trial version of the scale was applied to 283 randomly selected students from Ordu University in October 2012. The socio-demographic characteristics of the sample group which has an important place in statistical processes performed on the trial form of the scale is given in the following table.

Table 1. Socio-Demographic Characteristics of "Sample-1"

\begin{tabular}{lll}
\hline Gender & Number & \% \\
\hline Female & 193 & 68.2 \\
Male & 90 & 31.8 \\
\hline Economic situation & 10 & 3.5 \\
\hline Low & 203 & 71.7 \\
Medium & 63 & 22.3 \\
High & 7 & 2.5 \\
Very high & & \\
\hline Academic Department Attended & & 11.7 \\
\hline Vocational High School & 33 & 17.7 \\
Health High School & 50 & 50.9 \\
Faculty of Fine Arts & 144 & 19.8 \\
Faculty of Arts and Sciences & 56 & \\
Faculty of Agriculture & & \\
\hline Classes & & \\
\hline
\end{tabular}




\begin{tabular}{lll}
\hline 1 & 85 & 30.0 \\
2 & 70 & 24.7 \\
3 & 59 & 20.8 \\
4 & 69 & 24.4 \\
\hline
\end{tabular}

\section{Sample 2: Test Re-Test of the Scale}

For the second stage of the study, the internal consistency of the test was investigated by applying the test-retest form to 659 students at Ordu University in November, 2012. The characteristics of the sample group taken into consideration for form credibility are given in Table 2.

Table 2. Socio-Demographic Characteristics of "Sample-2"

\begin{tabular}{lll}
\hline Gender & Number & \% \\
\hline Female & 425 & 64.5 \\
Male & 234 & 35.5 \\
\hline Economic situation & & \\
\hline Low & 32 & 4.9 \\
Medium & 431 & 65.4 \\
High & 180 & 27.3 \\
Very high & 16 & 2.4 \\
\hline Academic Department Attended & & \\
\hline Health High School & 265 & 40.2 \\
Faculty of Fine Arts & 21 & 3.2 \\
Faculty of Arts and Sciences & 222 & 33.7 \\
Faculty of Agriculture & 128 & 19.4 \\
Faculty of Dentistry & 23 & 3.5 \\
\hline Classes & & \\
\hline 1 & 224 & 34.0 \\
2 & 188 & 28.5 \\
3 & 146 & 22.2 \\
4 & 101 & 25.3 \\
\hline
\end{tabular}

\section{Sample 3: Final form of the scale}

For the third stage of the study, an evaluation was made in terms of different variables and the Belonging to the University Scale was applied to 1265 university students from Ordu University in November 2012. The socio-demographic characteristics of the sample group to which the final version of the form was applied are given in the following table.

Table 3. Socio-Demographic Characteristics of "Sample-3"

\begin{tabular}{lll}
\hline Gender & Number & $\%$ \\
\hline Female & 636 & 50.2 \\
Male & 629 & 49.8 \\
\hline Economic situation & \multicolumn{2}{l}{} \\
\hline Low & 893 & 7.8 \\
Moderate & 326 & 63.4 \\
High & 38 & 25.8 \\
Very high & \multicolumn{3}{l}{} \\
\hline Academic Department Attended & 115 & 9.1 \\
\hline Vocational High School & 40 & 3.1 \\
Health High School & 26 & 2.0 \\
Faculty of Medicine & 21 & 1.7 \\
Faculty of Fine Arts & 12 & 1.0 \\
State Conservatory & 749 & 59.2 \\
Faculty of Arts and Sciences & 302 & 23.9 \\
Faculty of Agriculture & & \\
\hline
\end{tabular}




\begin{tabular}{lll}
\hline Classes & & \\
\hline 1 & 368 & 29.1 \\
2 & 366 & 28.9 \\
3 & 276 & 21.9 \\
4 & 255 & 20.1 \\
\hline
\end{tabular}

\subsection{Data Collection Tools Used in the Development of the Scale of Belonging to University}

The literature survey for the scale was conducted and the potential items related to the subject were determined. An "Expert Opinion Data Collection Form" was created in order to evaluate items on the crude scale in terms of content, spelling and grammar.

The "Belonging to the University Scale" was created as the data collection tool for the research.

\section{The Belonging to the University Scale (BUS)}

The Belonging to the university scale (BUS) is a measurement tool which aims to determine the satisfaction level of the belonging requirement of university students in the higher education institutions they attend. In the study, a 5-point Likert-type scale was created. While creating the scale, the necessary steps in the preparation process of the Likert-type scale were followed [22]. The scale consists of 14 items and 3 sub-dimensions. These sub-dimensions are defined as "Identification", "Motivation" and "Expectations".

\section{Data Collection}

In this study, written permission was obtained from Ordu University Rectorate. The data were collected by the researcher who administered the scale to students in university classrooms. The instructions about the data collection tool were read to the sample groups who participated, the necessary information was given, verbal consent was obtained and voluntary participation ensured. In the first application for testretest, the students were told they can use a nickname provided that they used the same nickname in the second test so some students used these nicknames instead of their names. The data collection instrument used in the study was applied to the sample group in the academic year of 2012-2013. There were no restrictions on duration when completing the scale. Students filled in the questionnaire anonymously. The duration to complete the scale was between 5-10 minutes.

\subsection{Analysis and Interpretation of the Data}

In the statistical analysis for the development of the inventory, the SPSS 15 and LISREL-8.15 programs were used.

The content validity and construct validity techniques were used for validity analysis.

\section{Content validity}

For this purpose, the belonging to school scales in the literature and their theoretical structures were examined, and then the belonging to the university expressions used in the scale were prepared.

It has been reported that one of the methods for content validity is to refer to an expert opinion [23, 24]. In this research, the "Expert Opinion Data Collection Form" was created in order to evaluate the items on the prepared raw scale in terms of content and spelling rules. The form prepared for content validity of the scale was delivered to nine academics in various universities working in this field. The academics were given an "Expert Opinion Data Collection Form" in which the aim of the study, the content and expectations for their assessment were included along with the items. The academics were informed about the purpose of research and their opinions about the raw scale were requested. By examining the evaluation forms for the scale in accordance with expert opinion, the items were revised.

\section{Construct validity}


For the construct validity of the scale, Principal Component Analysis (PCA) which is a factor analysis technique was used. This technique is a multivariate statistical method which enables size reduction and interpretation by explaining variance-covariance structure of a set of data consisting of variables with the help of a linear combination of these variables [25]. The appropriateness of the factor structure obtained through PCA analysis was tested with the Structural Equation Model.

\subsection{Investigation of Conformity for Data Factor Analysis}

At this stage, to determine the correlation between the variables, the correlation matrix was calculated. Additionally, in order to test the fit of the data for factor analysis, the consistency of the items was measured by using the Bartlett Sphericity Test. The Kaiser-Meyer-Olkin (KMO) coefficient was evaluated in order to test the adequacy of the sample size [26-28].

\section{Determination of the Number of Factors}

To determine the number of factors, the identification according to Eigenvalues method was used and the values of one and greater than one are considered as factors [29]. Karagoz and Kosterelioglu [30] later reported that, the total number of factors was determined according to determination techniques with the help of Accumulation Graphics (Screen Plot) which was developed by Lewis-Beck. The power of the factor was tested according to the proportion of factor variance, with a rate between $40 \%$ and $60 \%$ taken as the decisive value [31]. Independence, openness to interpretation and axis of rotation (rotation) were applied to the factors obtained with the Rotating Factor Matrix [28]. The data was used to name and interpret the factors after the determination of factor numbers. The Factor Model Matrix showing the factor loading was obtained by means of the SPSS program [27].

In the research, the size of the Belonging to the University Scale was determined according to the rotation, scatter diagram variance, eigenvalues and factor loads. The varimax method was used for the rotation process [31].

\section{Naming of factors}

It has been reported that naming the factors found in factor analysis is not an easy task. For example, unrelated variables may be collected in one factor; in such case the variables with the greatest factor load can be taken as a basis for naming [30]. The factors were determined by examining the literature information and expert opinion.

Accordingly the factors were named;

1. Identification Dimension ,

2. Motivation Dimension,

3. Expectations Dimension

\section{Confirmatory Factor Analysis}

In this study, the fit of the model obtained with Exploratory Factor Analysis was examined with the Confirmatory Factor Analysis method [32].

\subsection{Reliability Analysis and Interpretation of Data to Improve the Belonging to the University Scale}

To check the internal consistency the Belonging to the University Scale, items, total item correlations and Cronbach $\alpha$ reliability coefficient were used. Additionally, the Cronbach $\alpha$ reliability coefficient was examined for reliability in terms of internal consistency of the final form of the scale. The test-retest method was used to estimate the test reliability.

\section{Results and Discussion}




\subsection{Results and Discussion Related to Validity}

The sample size of the study was 283 , a subset of data obtained from 350 students of Ordu University. To determine whether the data obtained before factor analysis for the construct validity of the raw scale is suitable for factor analysis, the Kaiser-Meyer-Olkin (KMO) coefficient was calculated. The multivariate normal distribution of the data was tested with the Bartlett meaningfulness level. The KMO and Barlett sphericity test results of the trial form of the Belonging to the University Scale are given in Table 4.

Table 4. KMO and Barlett Test Values of the Trial form of Belonging to the University Scale (the 23rd item)

\begin{tabular}{lll}
\hline Kaiser-Meyer-Olkin (KMO) & & 0.833 \\
& Chi-square & 1163.469 \\
Bartlett Significance Test & sd & 91 \\
& p & $<0$ \\
\hline
\end{tabular}

According to Ustuner [33], Pullant has a suggestion the KMO value should be at least 0.60 to be suitable for factor analysis. In the Bartlett test, if the significance value is less than 0.05 , the multivariate data is said to have a normal distribution and the analysis can continue [34]. In the study, as seen in the table, the rates were 0.833 for the $\mathrm{KMO}$ value and $\mathrm{p}=.000$ for the Bartlett level. This situation indicates that the trial form data of the scale is suitable for factor analysis.

\subsection{Construct Validity}

For construct validity, exploratory factor analysis and confirmatory factor analysis were performed to test the obtained structure.

\section{Exploratory Factor Analysis}

Factor analysis was conducted, items with output values smaller than 0.2 were removed from the evaluation and factor analysis was repeated. According to this, covariance distribution of the scale is given in Table 5.

Table 5: Values of Common Factor Variance Distribution

\begin{tabular}{lll}
\hline Items on the scale & Start** & Output* \\
\hline s3. I can easily state all kinds of thoughts at university & 1.000 & 0.727 \\
s4. I regret that I chose this university & 1.000 & 0.601 \\
s5. I can fulfill various wishes at the university & 1.000 & 0.508 \\
s6. I am proud to be a student of this university & 1.000 & 0.501 \\
s9. This university is unfair & 1.000 & 0.510 \\
s11. I feel that I am hindered at this university & 1.000 & 0.658 \\
s12. Social activities at the university meet my expectations & 1.000 & 0.557 \\
s13. I am anxious when it is time to go to the university & 1.000 & 0.518 \\
s14. Free time passes well at the university & 1.000 & 0.592 \\
s15. I don't think they understand me at the university & 1.000 & 0.567 \\
s17. I express myself easily at the university & 1.000 & 0.623 \\
s18. My problems at the university are solved by the authorities & 1.000 & 0.543 \\
s20. My thoughts are valued in the university & 1.000 & 0.505 \\
s23. I feel I am valuable at the university & 1.000 & 0.524 \\
\hline
\end{tabular}

** Eigen Value Start, * Output Ratings

In the research, it was identified that the common variance values change between 0.501 and 0.727 and the majority of the variance related to the scale is explained.

Furthermore, in the development of the scale, the cross correlation coefficients in the Anti-image Covariance Matrix must be above 0.5 [35]. Anti-image Covariance Matrix values of the scale are above 0.5 as seen in Table 6 .

In exploratory factor analysis, the high correlation between variables is researched. As the correlation between the variables decreases, the confidence in the result of the factor analysis reduces. The variables which have very strong correlations will usually be in the same factor. As a result of this, the relationship 
of these variables will be strong within the factor they are in [27]. The correlation matrix of the study is presented in Table 7. When the table is analyzed, it was found that the correlation between the variables were high as the Pearson Correlation coefficients were determinative (Indicative Rate) $=0.015>0.00001$. 
Table 6. Anti -Image Matrix Values of Belonging to the University Scale

\begin{tabular}{|c|c|c|c|c|c|c|c|c|c|c|c|c|c|c|c|}
\hline & & s3 & s4 & s5 & s6 & s9 & s11 & s12 & s13 & s14 & s15 & s17 & s18 & s20 & s23 \\
\hline \multirow{14}{*}{ 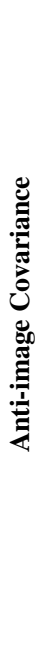 } & s3 & .652 & .036 & -.028 & .042 & -.117 & -.005 & .088 & .026 & .002 & .049 & -.260 & -.050 & -.045 & -.021 \\
\hline & s4 & .036 & .613 & .011 & -.147 & -.023 & -.124 & -.073 & -.182 & -.053 & -.067 & -.001 & .045 & -.074 & .022 \\
\hline & s5 & -.028 & .011 & .646 & -.078 & -.051 & .016 & -.118 & .018 & -.068 & .016 & -.087 & .005 & -.076 & -.098 \\
\hline & s6 & .042 & -.147 & -.078 & .654 & -.050 & .006 & -.039 & -.033 & -.050 & .025 & -.039 & -.138 & .035 & -.054 \\
\hline & s9 & -.117 & -.023 & -.051 & -.050 & .737 & -.098 & -.017 & -.076 & .025 & -.005 & .130 & -.099 & -.134 & .005 \\
\hline & s11 & -.005 & -.124 & .016 & .006 & -.098 & .562 & .020 & -.077 & .076 & -.258 & -.054 & .046 & .047 & -.103 \\
\hline & s12 & .088 & -.073 & -.118 & -.039 & -.017 & .020 & .708 & .049 & -.159 & .052 & -.020 & -.070 & -.071 & .009 \\
\hline & s13 & .026 & -.182 & .018 & -.033 & -.076 & -.077 & .049 & .732 & .003 & -.047 & -.073 & .027 & .017 & -.041 \\
\hline & s14 & .002 & -.053 & -.068 & -.050 & .025 & .076 & -.159 & .003 & .603 & -.028 & -.038 & -.056 & .079 & -.202 \\
\hline & s15 & .049 & -.067 & .016 & .025 & -.005 & -.258 & .052 & -.047 & -.028 & .613 & -.014 & -.085 & -.084 & .017 \\
\hline & s17 & -.260 & -.001 & -.087 & -.039 & .130 & -.054 & -.020 & -.073 & -.038 & -.014 & .523 & -.095 & -.089 & -.002 \\
\hline & s18 & -.050 & .045 & .005 & -.138 & -.099 & .046 & -.070 & .027 & -.056 & -.085 & -.095 & .563 & -.093 & -.071 \\
\hline & $\mathbf{s 2 0}$ & -.045 & -.074 & -.076 & .035 & -.134 & .047 & -.071 & .017 & .079 & -.084 & -.089 & -.093 & .612 & -097 \\
\hline & s23 & -.021 & .022 & -.098 & -.054 & .005 & -.103 & .009 & -.041 & -.202 & .017 & -.002 & -.071 & -.097 & .557 \\
\hline \multirow{14}{*}{ 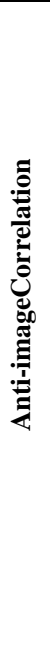 } & s3 & $.731(a)$ & .057 & -.043 & .064 & -.168 & -.009 & .130 & .037 & .004 & .077 & -.445 & -.083 & -.072 & -.035 \\
\hline & s4 & .057 & $.831(a)$ & .017 & -.233 & -.035 & -.211 & -.110 & -.271 & -.087 & -.110 & -.002 & .076 & -.121 & .037 \\
\hline & s5 & -.043 & .017 & $.907(a)$ & -.121 & -.073 & .027 & -.175 & .026 & -.109 & .025 & -.149 & .008 & -.121 & -.164 \\
\hline & s6 & .064 & -.233 & -.121 & $.885(a)$ & -.072 & .009 & -.058 & -.047 & -.080 & .040 & -.067 & -.227 & .056 & -.089 \\
\hline & s9 & -.168 & -.035 & -.073 & -.072 & $.810(a)$ & -.152 & -.023 & -.104 & .038 & -.008 & .210 & -.153 & -.200 & .008 \\
\hline & s11 & -.009 & -.211 & .027 & .009 & -.152 & $.739(a)$ & .032 & -.120 & .131 & -.439 & -.099 & .081 & .081 & -.185 \\
\hline & s12 & .130 & -.110 & -.175 & -.058 & -.023 & .032 & $.838(a)$ & .068 & -.244 & .078 & -.033 & -.111 & -.108 & .014 \\
\hline & s13 & .037 & -.271 & .026 & -.047 & -.104 & -.120 & .068 & $.849(a)$ & .005 & -.070 & -.118 & .041 & .025 & -.065 \\
\hline & s14 & .004 & -.087 & -.109 & -.080 & .038 & .131 & -.244 & .005 & $.815(a)$ & -.046 & -.068 & -.096 & .129 & -.349 \\
\hline & s15 & .077 & -.110 & .025 & .040 & -.008 & -.439 & .078 & -.070 & -.046 & $.781(\mathbf{a})$ & -.025 & -.145 & -.137 & .029 \\
\hline & s17 & -.445 & -.002 & -.149 & -.067 & .210 & -.099 & -.033 & -.118 & -.068 & -.025 & $.802(a)$ & -.175 & -.158 & -.004 \\
\hline & s18 & -.083 & .076 & .008 & -.227 & -.153 & .081 & -.111 & .041 & -.096 & -.145 & -.175 & $.881(a)$ & -.159 & -.127 \\
\hline & s20 & -.072 & -.121 & -.121 & .056 & -.200 & .081 & -.108 & .025 & .129 & -.137 & -.158 & -.159 & $.867(a)$ & -.166 \\
\hline & $\mathbf{s 2 3}$ & -.035 & .037 & -.164 & -.089 & .008 & -.185 & .014 & -.065 & -.349 & .029 & -.004 & -.127 & -.166 & $.867(\mathbf{a})$ \\
\hline
\end{tabular}

Table 7. Correlation Matrix Values of the Belonging to the University Scale 


\begin{tabular}{|c|c|c|c|c|c|c|c|c|c|c|c|c|c|c|c|}
\hline & & s3 & s4 & s5 & s6 & s9 & s11 & s12 & s13 & s14 & s15 & s17 & s18 & s20 & s23 \\
\hline \multirow{14}{*}{ نٍ } & s3 & 1.000 & .057 & .260 & .136 & .226 & .116 & .048 & .088 & .151 & .083 & .536 & .324 & .314 & .246 \\
\hline & s4 & .057 & 1.000 & .200 & .388 & .256 & .430 & .226 & .438 & .234 & .377 & .223 & .211 & .292 & .270 \\
\hline & s5 & .260 & .200 & 1.000 & .363 & .230 & .111 & .379 & .121 & .394 & .121 & .400 & .370 & .380 & .441 \\
\hline & s6 & .136 & .388 & .363 & 1.000 & .250 & .189 & .309 & .236 & .362 & .183 & .311 & .437 & .271 & .386 \\
\hline & s9 & .226 & .256 & .230 & .250 & 1.000 & .290 & .148 & .236 & .118 & .241 & .136 & .322 & .364 & .243 \\
\hline & s11 & .116 & .430 & .111 & .189 & .290 & 1.000 & .028 & .377 & .056 & .564 & .230 & .156 & .210 & .281 \\
\hline & s12 & .048 & .226 & .379 & .309 & .148 & .028 & 1.000 & .052 & .423 & .050 & .225 & .332 & .280 & .299 \\
\hline & s13 & .088 & .438 & .121 & .236 & .236 & .377 & .052 & 1.000 & .122 & .317 & .229 & .148 & .186 & .230 \\
\hline & s14 & .151 & .234 & .394 & .362 & .118 & .056 & .423 & .122 & 1.000 & .121 & .307 & .380 & .213 & .512 \\
\hline & s15 & .083 & .377 & .121 & .183 & .241 & .564 & .050 & .317 & .121 & 1.000 & .224 & .262 & .293 & .235 \\
\hline & s17 & .536 & .223 & .400 & .311 & .136 & .230 & .225 & .229 & .307 & .224 & 1.000 & .454 & .419 & .371 \\
\hline & s18 & .324 & .211 & .370 & .437 & .322 & .156 & .332 & .148 & .380 & .262 & .454 & 1.000 & .451 & .445 \\
\hline & s20 & .314 & .292 & .380 & .271 & .364 & .210 & .280 & .186 & .213 & .293 & .419 & .451 & 1.000 & .403 \\
\hline & s23 & .246 & .270 & .441 & .386 & .243 & .281 & .299 & .230 & .512 & .235 & .371 & .445 & .403 & 1.000 \\
\hline \multirow{14}{*}{ 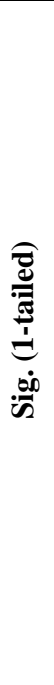 } & $\mathbf{s 3}$ & & .170 & .000 & .011 & .000 & .026 & .209 & .070 & .006 & .083 & .000 & .000 & .000 & .000 \\
\hline & s4 & .170 & & .000 & .000 & .000 & .000 & .000 & .000 & .000 & .000 & .000 & .000 & .000 & .000 \\
\hline & s5 & .000 & .000 & & .000 & .000 & .031 & .000 & .021 & .000 & .021 & .000 & .000 & .000 & .000 \\
\hline & s6 & .011 & .000 & .000 & & .000 & .001 & .000 & .000 & .000 & .001 & .000 & .000 & .000 & .000 \\
\hline & s9 & .000 & .000 & .000 & .000 & & .000 & .006 & .000 & .023 & .000 & .011 & .000 & .000 & .000 \\
\hline & s11 & .026 & .000 & .031 & .001 & .000 & & .322 & .000 & .175 & .000 & .000 & .004 & .000 & .000 \\
\hline & s12 & .209 & .000 & .000 & .000 & .006 & .322 & & .190 & .000 & .202 & .000 & .000 & .000 & .000 \\
\hline & s13 & .070 & .000 & .021 & .000 & .000 & .000 & .190 & & .020 & .000 & .000 & .006 & .001 & .000 \\
\hline & s14 & .006 & .000 & .000 & .000 & .023 & .175 & .000 & .020 & & .021 & .000 & .000 & .000 & .000 \\
\hline & s15 & .083 & .000 & .021 & .001 & .000 & .000 & .202 & .000 & .021 & & .000 & .000 & .000 & .000 \\
\hline & s17 & .000 & .000 & .000 & .000 & .011 & .000 & .000 & .000 & .000 & .000 & & .000 & .000 & .000 \\
\hline & s18 & .000 & .000 & .000 & .000 & .000 & .004 & .000 & .006 & .000 & .000 & .000 & & .000 & .000 \\
\hline & s20 & .000 & .000 & .000 & .000 & .000 & .000 & .000 & .001 & .000 & .000 & .000 & .000 & & .000 \\
\hline & s23 & .000 & .000 & .000 & .000 & .000 & .000 & .000 & .000 & .000 & .000 & .000 & .000 & .000 & \\
\hline
\end{tabular}


In this study, the eigenvalues of the factor analysis for the 14 items remaining from the 23 initial items on the scale and the values related to the variances which the dimensions explain are given in Table 8 .

Table 8. Eigenvalues of the Belonging to the University Scale and Values related to Total Variances described

\begin{tabular}{|c|c|c|c|c|c|c|c|c|c|}
\hline \multirow[b]{2}{*}{ 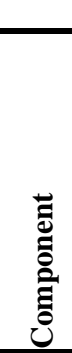 } & \multicolumn{3}{|c|}{ Initial eigenvalues Load } & by & $\begin{array}{l}\text { ctors } \\
\text { ues Loa }\end{array}$ & & \multicolumn{3}{|c|}{ Values after rotation } \\
\hline & 苞 & 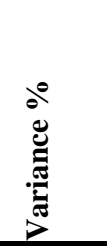 & 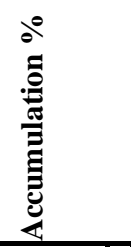 & 矛 & 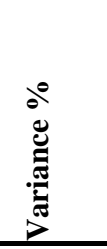 & 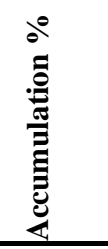 & है & 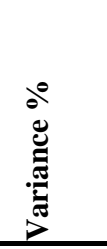 & 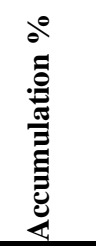 \\
\hline 1 & 4.570 & 32.642 & 32.642 & 4.570 & 32.642 & 32.642 & 2.780 & 19.855 & 19.855 \\
\hline 2 & 1.793 & 12.810 & 45.451 & 1.793 & 12.810 & 45.451 & 2.559 & 18.276 & 38.131 \\
\hline 3 & 1.272 & 9.083 & 54.534 & 1.272 & 9.083 & 54.534 & 2.297 & 16.404 & 54.534 \\
\hline 4 & 0.909 & 6.491 & 61.026 & & & & & & \\
\hline 5 & 0.793 & 5.667 & 66.693 & & & & & & \\
\hline 6 & 0.704 & 5.026 & 71.718 & & & & & & \\
\hline 7 & 0.680 & 4.860 & 76.578 & & & & & & \\
\hline 8 & 0.603 & 4.307 & 80.885 & & & & & & \\
\hline 9 & 0.593 & 4.239 & 85.124 & & & & & & \\
\hline 10 & 0.530 & 3.789 & 88.913 & & & & & & \\
\hline 11 & 0.469 & 3.350 & 92.263 & & & & & & \\
\hline 12 & 0.395 & 2.823 & 95.086 & & & & & & \\
\hline 13 & 0.371 & 2.653 & 97.740 & & & & & & \\
\hline 14 & 0.316 & 2.260 & 100.000 & & & & & & \\
\hline
\end{tabular}

In social sciences, the variance ratios ranging between $40 \%$ and $60 \%$ are considered ideal [34]. In the research, the explanation rate of total variance of the three dimensions of the scale was found to be as high as $54.534 \%$.

The eigenvalue ratio used to decide the factor number and the calculation of variance explained by factors is generally 1 and more than 1 [34]. Considering the eigenvalues of the Belonging to the University Scale, three factors above 1 were observed.

For the size selection, the number of dimensions can be decided by looking at the screen plot (accumulation graph). The accumulation chart is given in Figure 1.

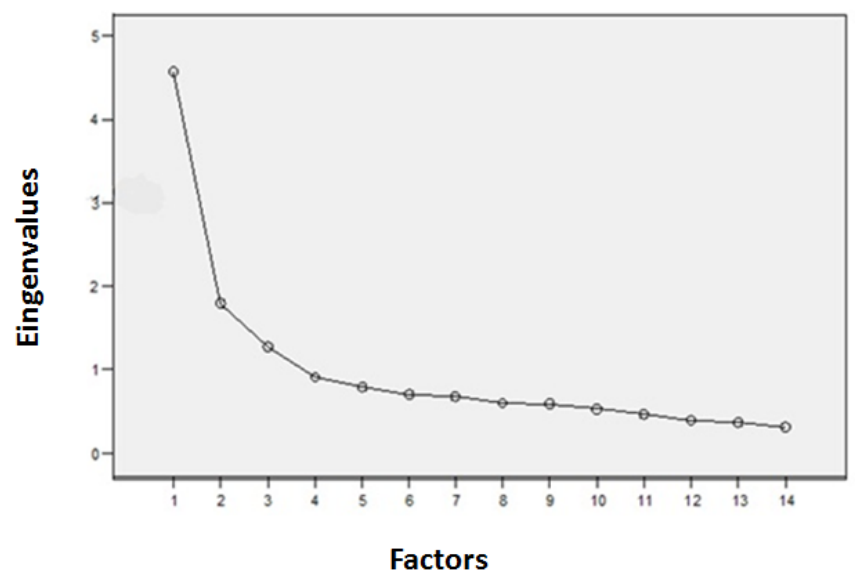

Figure 1: The Accumulation Graph of the Belonging to the University Scale 
When the chart is examined, three factors above one are seen.

Gathering the question items into one factor of the developing scale after factor analysis and the values of factor loads before rotation are generally an indication of the strength of the factor structure [35]. As shown in Table 9, the 0.40 and above 0.40 factor loadings of the Belonging to the University Scale are related to each other and gathered in a single factor.

Table 9. Factor Load Values of items on the Belonging to the University Scale before Rotation

\begin{tabular}{lccc}
\hline Items on the Scale & & Factors & \\
\hline & $\begin{array}{c}\text { First } \\
\text { factor }\end{array}$ & $\begin{array}{c}\text { Second } \\
\text { factor }\end{array}$ & $\begin{array}{c}\text { Third } \\
\text { factor }\end{array}$ \\
\hline s23. I feel I am valuable at the university & $\mathbf{0 . 6 9 9}$ & & \\
s18. My problems at the university are solved by the authorities & $\mathbf{0 . 6 9 2}$ & & \\
s20. My thoughts are valued in the university & $\mathbf{0 . 6 5 4}$ & & $\mathbf{0 . 4 1 2}$ \\
s17. I express myself easily at the university & $\mathbf{0 . 6 5 1}$ & & \\
s6. I am proud to be a student of this university & $\mathbf{0 . 6 2 2}$ & & \\
s5. I can fulfill various wishes at the university & $\mathbf{0 . 6 2 0}$ & & \\
s14. Free time passes well at the university & $\mathbf{0 . 5 6 9}$ & & \\
s4. I regret that I chose this university & $\mathbf{0 . 5 6 5}$ & $\mathbf{0 . 4 3 1}$ & \\
s9. This university is unfair & $\mathbf{0 . 4 9 4}$ & & \\
s12. Social activities at the university meet my expectations & $\mathbf{0 . 4 8 2}$ & & \\
s11. I feel that I am hindered at the university & $\mathbf{0 . 4 7 7}$ & $\mathbf{0 . 6 5 5}$ & \\
s15. I don't think they understand me at the university & $\mathbf{0 . 4 8 8}$ & $\mathbf{0 . 5 7 2}$ & \\
s13. I am anxious when it is time to go to the university & $\mathbf{0 . 4 4 5}$ & $\mathbf{0 . 5 0 7}$ & \\
s3. I can easily state all kinds of thoughts at the university & $\mathbf{0 . 4 4 4}$ & & $\mathbf{0 . 7 0 1}$ \\
\hline
\end{tabular}

Akdag explained the evaluation of the item loading factor values as follows;

"There is a common view that the value of factor load of the item should have a minimum of 0:30. Items under this weight limit are eliminated. The value of the load should be $0.32,0.40$, and 0.45 . Regardless of the signaling, 0.60 and higher load value is defined as high with load value between 0:30 and 0:59 defined as moderate size. As the sample size increases, the load value to be taken into consideration reduces.

For example;

- The sample size must be at least 350 for the loading value of 0.30 ,

- The sample size must be at least 200 for the loading value of 0.40 ,

- The sample size must be at least 120 for the loading value of 0.50 ,

- The sample size must be at least 85 for the loading value of 0.60 ,

- The sample size must be at least 60 for the loading value of 0.70 ,

[34].

As shown in Table 9, since the loading value for the sample size of 283 is 0.40 and above, values were included in the review.

In the distribution of load factors obtained as a result of the varimax rotation, the questions included in more than one factor or with a value less than 0.10 between the factors loadings should be removed [35]. According to exploratory factor analysis, after removing some items from the scale, the factor in which each item is located and the load of the item in the factor are given in Table 10. 
Table 10. Factor Load Values of items on the Belonging to the University Scale after Rotation

\begin{tabular}{|c|c|c|c|}
\hline \multirow[b]{2}{*}{ Items on the Scale } & \multicolumn{3}{|c|}{ Factor Loads } \\
\hline & $\begin{array}{c}\text { First } \\
\text { dimension }\end{array}$ & $\begin{array}{c}\text { Second } \\
\text { dimension }\end{array}$ & $\begin{array}{c}\text { Third } \\
\text { dimension }\end{array}$ \\
\hline s14. Free time passes well at the university & 0.761 & & \\
\hline s12. Social activities at the university meet my expectations & 0.746 & & \\
\hline s6. I am proud to be a student of this university & 0.615 & & \\
\hline s5. I can fulfill various wishes at the university & 0.599 & & \\
\hline s23. I feel I am valuable at the university & 0.591 & & \\
\hline s11. I feel that I am hindered at the university & & 0.798 & \\
\hline s15. I don't think they understand me at the university & & 0.735 & \\
\hline s4. I regret that I chose this university & & 0.696 & \\
\hline s13. I am anxious when it is time to go to the university & & 0.672 & \\
\hline s9. This university is unfair & & 0.502 & \\
\hline s3. I can easily state all kinds of thoughts at the university & & & 0.852 \\
\hline s17. I express myself easily at the university & & & 0.728 \\
\hline s20. My thoughts are valued in the university & & & 0.563 \\
\hline s18. My problems at the university are solved by the authorities & & & 0.521 \\
\hline
\end{tabular}

There must be at least three or four items in each sub-factor [34]. When Table 10 is examined, there are at least four items in each sub-factor of the developed scale.

The dimensions obtained by considering the meanings that the items carry and benefiting from recycled factor loads are expectations, motivation and identification, respectively. The resulting dimensions and related conditions are given in Table 11.

Table 11. Dimensions of the Belonging to the University Scale and the Values of Related Items

\begin{tabular}{lll}
\hline Scale Size & \multicolumn{1}{c}{ Related Items } & $\begin{array}{l}\text { Minimum and Maximum Points } \\
\text { Obtainable from the Dimensions }\end{array}$ \\
\hline Expectations & $14,12,6,5,23$ & $5-25$ \\
Motivation & $11,15,4,13,9$ & $5-25$ \\
Identification & $3,17,20,18$ & $4-20$ \\
\hline
\end{tabular}

\section{Minimum and Maximum Points Obtainable from the Dimensions}

The targets to be measured by the items forming the sub-dimensions of the scale are as follows;

1. Expectation Size; these are expressions which measure the student's perceptions about how their experience corresponds with their pre-college expectations related to university and expectations related to the educational process.

2. Motivation Size; these include statements relating to the student's motivation about reaching targets in the academic and social fields in university and university-based relationships

3. Identification Size; these are expressions measuring the relationship of the student with the university and the student's intellectual and emotional perceptual tendency related to the university.

\section{Confirmatory Factor Analysis}

In order to test whether the three-factor model obtained by exploratory factor analysis satisfies the fit of the data or not, confirmatory factor analysis was performed. LISREL software was utilized for this purpose. The covariance matrix was prepared by transferring the data set obtained from 283 people used for exploratory factor analysis into the program. 
In order to improve the three-factor model of the Belonging to the University Scale, the modification proposals were investigated. The definition of the relationship between the error variances of items 3 and 17 in factor $\mathrm{C}$ and items 11 and 15 in factor $\mathrm{B}$ was proposed. When the item contents are analyzed, it was seen that both of them were expressed in a similar way and the suggested modification was performed. After the modification, a decline in the value of chi-square was observed [The chi-square difference respectively in one degree of freedom for two modifications was $=35.89(\mathrm{P}=0.0)$ and 21:02 $(\mathrm{P}=0.0)$ ]. The ultimate goodness-of-fit values of the models obtained after modification (Table 12), standardized factor loadings, variances (R2), t values (Table 13) and path diagram (Figure 2) are presented below.

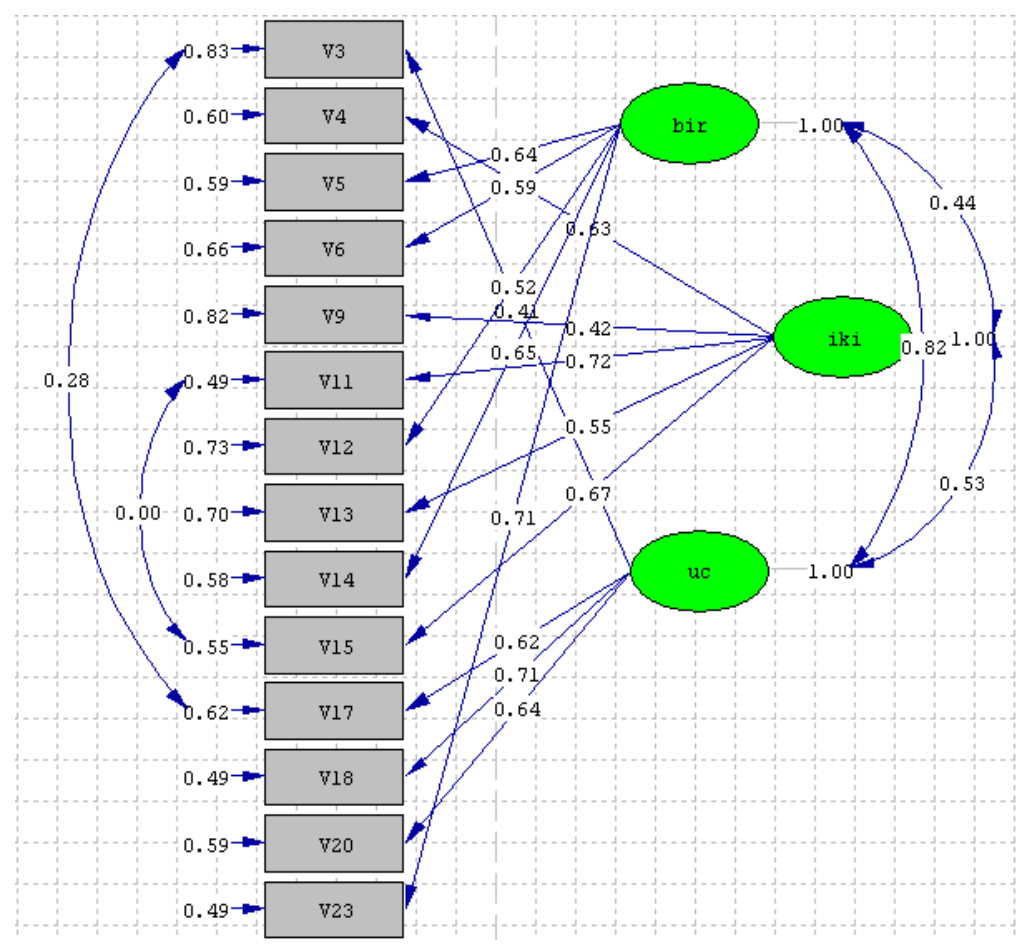

Figure 2. Path Diagram Regarding the Three-Factor Structure of the Scale

None of the standardized parameter values in the path diagram are over 1 [36]. These values indicate that the model has no serious problems $[36,37]$.

Table 12. Confirmatory Factor Analysis Results for the Three Factor Model of the Scale

\begin{tabular}{lccr}
\hline $\begin{array}{c}\text { Goodness of fit } \\
\text { values }\end{array}$ & Excellent & Acceptable & Three-factor model. \\
\hline $\mathbf{p}^{*}$ & $>.01$ ya da .05 & $<.01$ ya da .05 & $0.000(\mathrm{~K})$ \\
$\boldsymbol{X}^{2} /$ sd & $\leq 2$ & $2-5$ & $161.90 / 72=2.24(\mathrm{~K})$ \\
RMSEA & $0.00<\mathrm{RMSEA}<0.05$ & $0.05<\mathrm{RMSA}<0.10$ & $0.067(\mathrm{~K})$ \\
RMR & $0 \leq \mathrm{RMR} \leq 0,05$ & $0.05<\mathrm{RMR} \leq 0,10$ & $0.073(\mathrm{~K})$ \\
SRMR & $0.00<\mathrm{SRMR}<0.05$ & $0.05<\mathrm{SRMR}<0.10$ & $0.060(\mathrm{~K})$ \\
GIF & $0.95<\mathrm{GFI}<1.00$ & $0.90<\mathrm{GFI}<0.95$ & $0.92(\mathrm{~K})$ \\
AGFI & $0.90<\mathrm{AGFI}<1.00$ & $0.85<\mathrm{AGFI}<0.90$ & 0.89 \\
CFI & $0.95<\mathrm{CFI}<1.00$ & $0.90<\mathrm{CFI}<0.95$ & $0.91(\mathrm{~K})$ \\
NFI & $0.95<\mathrm{NFI}<1.00$ & $0.90<\mathrm{NFI}<0.95$ & 0.86 \\
NNFI & $0.97 \leq \mathrm{NNFI} \leq 1$ & $0.95 \leq \mathrm{NNFI} \leq 0,97$ & 0.89 \\
\hline
\end{tabular}

The value $\mathrm{p}^{*}=000$ indicates that there is no difference between the observed and expected covariance matrices and confirms the model [37].

Table 12 was examined according to the fit index of the model obtained as a result of confirmatory factor analysis of the Belonging to the University Scale and RMSEA (Root Mean Square Error of Approximation), AGFI (adjusted goodness of fit index), GFI (goodness of fit index), CFI (comparative 
fit index), and RMR (root mean square residual) compliance statistics of the 3-factor model were found to be within the acceptable range $[32,38,39]$.

Table 13: Standardized Factor Loads, $R 2$ and $t$ Values related to the Three Factor Structure of the Scale

\begin{tabular}{|c|c|c|c|}
\hline Items & $\begin{array}{c}\text { Standardized Factor } \\
\text { Loadings }\end{array}$ & $\mathbf{R}^{2}$ & $\mathbf{t}$ \\
\hline Expectation & & 0.39 & \\
\hline s14. Free time passes well at the university & 0.65 & 0.42 & 11 \\
\hline s12. Social activities at the university meet my expectations & 0.52 & 0.27 & 8.43 \\
\hline s5. I can fulfill various wishes at the university & 0.64 & 0.41 & 10.81 \\
\hline s6. I am proud to be a student of this university & 0.59 & 0.35 & 9.75 \\
\hline s23. I feel I am valuable at the university & 0.71 & 0.50 & 12.44 \\
\hline Motivation & & 0.37 & \\
\hline s11. I feel that I am hindered at the university & 0.72 & 0.52 & 11.98 \\
\hline s15. I don't think they understand me at the university & 0.67 & 0.45 & 11.13 \\
\hline s13. I am anxious when it is time to go to the university & 0.55 & 0.30 & 8.76 \\
\hline s4. I regret that I chose this university & 0.63 & 0.40 & 9.75 \\
\hline s9. This university is unfair & 0.42 & 0.18 & 6.52 \\
\hline Identification & & 0.37 & \\
\hline s3. I can easily state all kinds of thoughts at the university & 0.41 & 0.17 & 6.32 \\
\hline s17. I express myself easily at the university & 0.62 & 0.38 & 10.18 \\
\hline s20. My thoughts are valued in the university & 0.64 & 0.41 & 10.55 \\
\hline s18. My problems at the university are solved by the authorities & 0.71 & 0.50 & 12.06 \\
\hline
\end{tabular}

The standardized factor loading for the three-factor structure of the scale is 1.96 at $0.05 \mathrm{t}$ value and the items with this value are considered significant [36].

As a result, it was identified that factor analysis and confirmatory factor analysis values give similar results, although there are relatively small differences between the values observed. When the results were evaluated, the size of the items and the number of items are found to be the same.

\subsection{Results and Discussion of Reliability}

Within the scope of the research, as the scale is multidimensional, the reliability of the Belonging to the University Scale was examined by calculation of internal consistency coefficient of each sub-dimension and test-retest methods.

\section{Internal Consistency}

The Cronbach's $\alpha$ coefficient were calculated for 14 items selected for the final scale of the inventory. Calculations were made for "Sample-1" group consisting of 283 students and for "Sample-3" group consisting of 1265 people. Cronbach's $\alpha$ coefficient are given in Table 14.

Table 14. Belonging to the University Scale and Cronbach's a Coefficients of the Scale Dimensions

\begin{tabular}{lrclcc}
\hline & \multicolumn{3}{c}{ CrudeTest $\mathbf{n}=\mathbf{2 8 3}$} & \multicolumn{3}{c}{ Final test $\mathbf{n}=\mathbf{1 2 6 5}$} \\
\hline & Items on BUS & Cronbach $\boldsymbol{\alpha}$ & Items on BUS & Cronbach $\boldsymbol{\alpha}$ \\
\hline Total & $5,6,12,14,23$ & 0.834 & Total & $5,6,12,14,23$ & 0.750 \\
& $4,9,11,13,15$ & & & $4,9,11,13,15$ & \\
& $3,17,18,20$ & & & $3,17,18,20$ & \\
Expectation & & & & & \\
Motivation & $5,6,12,14,23$ & 0.755 & Expectation & $5,6,12,14,23$ & 0.722 \\
Identification & $4,9,11,13,15$ & 0.728 & Motivation & $4,9,11,13,15$ & 0.705 \\
\hline
\end{tabular}

When the table is analyzed, it is seen that the Cronbach's $\alpha$ reliability values obtained for the research are acceptable. The correlation values of each of the 14 items on the scale are given in Table 15. 
Table 15. Total correlation values of Dimensions and Items

\begin{tabular}{lcc}
\hline Dimensions & Items & Total Correlation Values \\
\hline & 12 & 0.471 \\
Expectations & 14 & 0.584 \\
& 23 & 0.562 \\
& 5 & 0.537 \\
& 6 & 0.475 \\
\hline \multirow{3}{*}{ Motivation } & 11 & 0.592 \\
& 13 & 0.475 \\
& 15 & 0.525 \\
Identification & 4 & 0.527 \\
& 9 & 0.341 \\
\hline
\end{tabular}

According to Akdag, the items with correlation coefficients less than 20 are deducted. These coefficients are also the discrimination indices for the items [34].

When Table 15 is examined, there is no value below 0.20 .

\section{Test-Retest}

Within the scope of the test-retest of reliability of the Belonging to the University Scale, after the final form of the scale was created, it was applied to 659 students forming a sample group separate from the "Sample-1" and "Sample-3" groups twice at two week intervals in November 2012. The correlation coefficients for the subscales in both applications of the final form are interpreted as a test-retest reliability value for the final inventory.

The test-retest reliability correlation values related to the subscales of the Belonging to the University Scale are given in Table 16.

Table 16: Correlation Reliability Values Related to the Belonging to the University Scale and Dimensions

\begin{tabular}{ll}
\hline Sub-dimensions & test-retest $\mathbf{n}=\mathbf{6 5 9}$ \\
\hline First group $\mathbf{( 3 , 4 , 7 , 9 , 1 4 )}$ & 0.87 \\
& \\
Second group $(\mathbf{2 , 5 , 6 , 8 , 1 0 )}$ & 0.84 \\
Third group $(\mathbf{1 , 1 1 , 1 2 , 1 3 )}$ & 0.83 \\
General & 0.88 \\
\hline
\end{tabular}

When the values in the table are examined, it is observed that the correlation values for the subscales of the Belonging to the University Scale range between 0.83 and 0.87 . These values show that the scale gives similar results and each dimension is highly reliable when it is applied to the same sample group at regular intervals.

When the pretest - posttest research design is applied for dependent groups, the results must be tested with the independent group's t-test. In the "Paired Samples Test" table, the p-value is checked. If it is $<0.05$, it means there is a significant difference between two measurements [40]. This process must be performed for the immutability of the total average score of pretest and posttest in each sub-dimension [41]. The scale values for the t-test are given in Tables 17, 18 and 19.

According to Table 17, the $\mathrm{N}$ number is 659 in both groups and so, it shows that there is no lost value and the same people have been reached during both applications. In the application of the Belonging to the University Scale, a minimum of 14 and maximum of 70 points can be obtained. Evaluation points from 5-41 indicate the subject does not feel they belong to the university, while those with points from 42-70 feel they belong to the university.

Table 17: Descriptor Values belonging to the Size Totals 


\begin{tabular}{lccccc}
\hline Dimensions & $\mathbf{N}$ & Min & Max & $\bar{X}$ & SS \\
\hline Expectation & 659 & 5 & 25 & 13.52 & 3.853 \\
Motivation & 659 & 5 & 25 & 15.86 & 3.815 \\
Identification & 659 & 4 & 20 & 12.20 & 3.267 \\
Total & 659 & 18 & 69 & 41.58 & 8.801 \\
\hline Expectation & 659 & 5 & 25 & 13.54 & 3.895 \\
Motivation & 659 & 5 & 25 & 15.96 & 3.960 \\
Identification & 659 & 4 & 20 & 12.22 & 3.256 \\
Total & 659 & 18 & 69 & 41.73 & 9.004 \\
\hline
\end{tabular}

* The averages of the lowest and highest value scores given by the students for the applied scale.

Table 18. Mean and Standard Deviation Values in the Dependent Samples

\begin{tabular}{lllll}
\hline & \multicolumn{1}{c}{ Dimensions } & $\bar{X}$ & N & SS \\
\hline \multirow{2}{*}{ 1 Match } & Expectation First Application & 13.52 & 659 & 3.853 \\
& Expectation Second Application & 13.54 & 659 & 3.895 \\
\hline \multirow{2}{*}{ 2 Match } & Motivation First Application & 15.86 & 659 & 3.815 \\
& Motivation & 15.96 & 659 & 3.960 \\
\hline \multirow{2}{*}{ 3 Match } & Identification First Application & 12.20 & 659 & 3.267 \\
& Identification & 12.22 & 659 & 3.256 \\
\hline \multirow{2}{*}{ 4 Match } & Total First Application & 41.58 & 659 & 8.801 \\
& Total & 41.73 & 659 & 9.004 \\
\hline
\end{tabular}

The average of the first application and the second application must be very close to each other [41]. When Table 18 is examined, between the two applications a difference was found in Expectation Size of 0.02, in Motivation Size of 0.1, in Identification Size of 0.02 and in total of 0.15.

When the table is examined, it was determined that there was no significant difference between the averages of the total scores obtained from the first application and second application for each dimension ( $p>0.05$ ). This situation is indicative of the constancy between the pretest and posttest.

Table 19. T-test Values in the Dependent Samples

\begin{tabular}{lllllll}
\hline \multicolumn{1}{c}{ Sub Dimensions } & $\bar{X}$ & SS & t & Sd & P Value \\
\hline Expectation & First -Second Application & -0.027 & 2.001 & -0.350 & 658 & 0.726 \\
Motivation & First -Second Application & -0.096 & 2.076 & -1.182 & 658 & 0.238 \\
Identification & First -Second Application & -0.024 & 1.837 & -0.339 & 658 & 0.735 \\
Total & First-Second Application & -0.147 & 4.146 & -0.911 & 658 & 0.362 \\
\hline
\end{tabular}




\section{Usefulness of the Belonging to the University Scale}

According to Turgut [42], some measures such as being economic, suitability in terms of administration time and ease of scoring and interpretation are criteria for a useful measuring tool. The Belonging to the University Scale is a scale consisting of 14 items. As the implementation period lasts approximately 510 minutes, it is very useful in terms of time.

\section{Conclusions and Recommendations}

In conclusion, the "Belonging to the University Scale" (BUS) is reliable, valid and useful. The inclusion of factors such as increasing absenteeism from lessons among university students, increasing tendency toward violence, use of drugs, depression, stress, school success and graduation problems under the heading of an unfulfilled need to belong means this topic requires detailed research and study. The need for universities to find quality students to fill required quotas is pressing and the loss of these students forms a significant problem. In the present day due to intense competition between universities, the losses to universities in terms of budgets and image make it harder to compensate. In this light, the BUS will play an important role in data collection and strategy formation during these studies.

BUS may be adapted for use at other educational stages apart from universities (preschool, primary school, middle school and high school). In high schools, especially, the adapted BUS may play an effective role in data collection for evaluation of the belonging factor in the resolution of problems such as violence, use of drugs, absenteeism and depression observed recently throughout the world. Additionally, the feeling of belonging needs to be fulfilled in all areas of life, and it may be a guide for the development of scales for family and working life.

The BUS may be used by psychological counseling and guidance services operating under the medicosocial services in universities and in individual and group counseling by other psychological counseling services.

The BUS structure may be adapted and if necessary revised in the future in light of the dynamic university process, differentiation of education methods and differences in the effect of psycho-social changes on the individual.

\section{References}

[1] Cuceloglu, D. (2006), Child-Centered Family To Be. Dogan Cuceloglu Official Web Site Articles. http://www.dogancuceloglu.net/yazilar/67-cocuk-merkezli-aile-olmak [20.04.2016].

[2] Adler, A. (1929), The Practice and the Theory of Individual Psychology, London: Routh ledge and Kagan Paul.

[3] Glasser, W. (2000), Reality Therapy in the Year 2000. https://www.researchgate.net/publication/265565283_Reality_Therapy_in_Reality_Therapy_in the Year 2000 [20.04.2016]

[4] Keenan, K. (1996), Motivasyon. (Translation: Koporan, E.). Istanbul: Remzi Bookstore

[5] Ozden, Y. (1999), Learning and Teaching (3rd edition), Ankara: Pegem A Publishing

[6] Usta, A. (2009), A Socio-Psychological Evaluation on Ethnic Violence Phenomenon, Turkish Journal of Police Studies. 11(2), 87-106

[7] Baumeister, Rf., \& Leary, Mr. (1995), The need to belong: Desire for interpersonal attachments as a fundamental human motivation. Psychological Bulletin, 117, 497-529.

[8] Knack, Jm. (2006), Re-Experiencing Social Versus Physlcal Pain And Its Influence On SelfRegulatory Reserve. Presented to the Faculty of the Graduate School of The University of Texas at Arlington in Partial Fulfillment of the Requirements for the Degree of Master Of Science In Psychology. Texas. 
[9] Aypay, A., Sever, M., Demirhan, G. (2012), Social and Academic Integration of University Students: A Longitudinal Study, University of Gaziantep Journal of Social Sciences, 11(2), 407422

[10] Ma, X. (2003), Sense of Belonging to School: Can Schools Make a Difference? The Journal of Educational Research, 96(6), 340-349

[11] Dana, E., Kelly, G., Claudia, F., Yancey, W. (2004), The Relationship between Social Interest and Coping Resources in Children, American School Counselors Association, 7(3), 178-186

[12] Pittman, L. D. and Richmond, A. (2008), University belonging, friendship quality and psychological adjustment during the transition to college. The journal of Experimental Education, 76(4), 343-361.

[13] Battistich, V., Solomon, D., Watson, M., \& Schaps, E. (1997), Caring school communities. Educational Psychologist, 32, 137-151

[14] Walter, Sm, Lambie, Gw., \& Ngazimbi, Ee. (2008), A Choice Theory Counseling Group Succeeds with Middle School Students Who Displayed Disciplinary Problems, Middle School Journal, 40(2),4-12

[15] Gilligan, R. (2000), Adversity, resilience and young people: The protective value of positive school and spare time experiences. Children and Society, 14, 37-47

[16] Roeser, Rw., Midgley, C., \& Urdan, Tc. (1996), Perceptions of the school psychological environment and early adolescents' psychological and behavioral functioning in school: The mediating role of goals and belonging, Journal of Educational Psychology, 88, 408-422

[17] Osterman, Fk. (2000), "Students Need for Belonging in the School Community", Review of Educational Research, 17(3), 323-367

[18] Lambert, A. (2010), Social Class and the College Experience Of Students In Kentucky: An Exploratory Study. Occasional Research Paper, 16, 1-17

[19] Finn, Jd. (1989), withdraws from school. Review of Educational Research, 59, 117-142

[20] Furrer, C., Skinner, E. (2003), Sense of relatedness as a factor in children's academic engagement and performance, Journal of Educational Psychology, 95(1), 148-162.

[21] Anderman, E. M. (2002). School Effects on Psychological Outcomes during Adolescence. Journal of Educational Psychology, 94(4), 795-809.

[22] http://www.conqir-idr.org/literature/LikertAppendix-1.pdf [20.04.2016].

[23] Anastasi, A. (1976). Psychological Testing. (Fifth Edition). New York: Macmillan Publishing Co., Inc.

[24] Karasar, N. (2005), Scientific Research Method, Ankara: Nobel Publishing

[25] Yazar, I., Yavuz, Hs., Cay, M.A. (2009), Face Recognition Applicatıons of Principle Component Analysis Method and Some of Its Classical and Robust Variants. Journal of Engineering and Architecture Faculty of Eskisehir Osmangazi University 22(1): 49-63

[26] Akgul, A. and Cevik, O. (2003), Statistical Analysis Techniques, Ankara: Emek, Ofset

[27] Nakip, M. (2003), Marketing Research Techniques and (SPSS Supported) Applications, Ankara: Seckin Publishing.

[28] Buyukozturk, S. (2008). Data Analysis for the Social Sciences Handbook, Ankara: Pegem Akademi

[29] Ozdamar, K. (2002), Package Programs with Statistical Data Analysis. Eskisehir. Kaan Bookstore. 
[30] Karagoz, Y., Kosterelioglu I. (2008), Developing Evaluation Scale of Communication Skills with Factor Analysis Dumlupinar University. Journal of Social Sciences. 21, 81-98

[31] Tavsanc1l, E. (2002), Measurement of Attitudes and Data Analysis with SPSS, Ankara: Nobel Publishing.

[32] Erdogan, Y., Bayram, S., Deniz, L. (2007), Web-based teaching attitude scales: exploratory and confirmatory factor analysis. Journal of Human Sciences, 4(2).1-14

[33] Ustuner, M. (2006), Reliability And Validity Study Of An Attitude Scale of Teaching Profession, Educational Administration: Theory and Practice 45,109-127

[34] Akdag, M. (2011), Statistical Analysis with SPSS. Lecture Notes. Malatya. https://docs.google.com/viewer?a=v\&q=cache:UsgOKBj_ltEJ:iys.inonu.edu.tr/webpanel/dosyal ar/669/file/SPSS\%2520testleri.doc+spss\%E2\%80\%99de+istatistiksel+analizler+mustafa+akda \%C4\%9F\&hl=tr\&pid=bl\&srcid=ADGEESjOtwpP0jpkhYv2mJs9Fa3aNd 0eSTtnr475UPtNgci XbQPNcM3TvrExwJTrdaOoG-xYATN4V8gjHEp0oBS-VLbnJPkGh-

GKL ukbtwhDc5OT8NXi6RihLYapmoEUU97BB2nGYt\&sig=AHIEtbR2aJMXHd3hZODTHf lhv1VsmpvrkA [10.08.2012]

[35] Koseoglu, K. (2007), Spss Manuel. Yeditepe Unv. Research Meth.2. http://temelistatistik.files.wordpress.com/2011/05/analiz-menusu.pdf [20.04.2016]

[36] Simsek, Of. (2007), Introduction to Structural Equation Modeling: Basic Principles and Applications LISREL, Ankara: Ekinoks Publishing

[37] Cokluk, O., Sekercioglu, G. ve Buyukozturk, S. (2010), Multivariate Statistics for the Social Sciences: SPSS and LISREL Applications, Ankara: Pegem A Publishing

[38] Apaydin, C, Kizılhan, P. (2011), A Second - Order Factor Analysis of the Classroom Learning Environment in Faculties, Educational Administration: Theory and Practice, 17(4), 509-526

[39] Tezcan, C. (2008), Structural Equation Models, Hacettepe University Department of Statistics. Unpublished Master's Thesis, Ankara.

[40] Turan, I. (2012), Basic Statistics. Lecture Notes. http://docplayer.biz.tr/7981627-Temel-istatistik2012-y-doc-dr-ibrahim-turan-spss-analiz-menusu.html [20.04.2016]

[41] Eymen, Ue. (2007). SPSS 15, the Data Analysis Methods. Statistics Center Publication No. 1 http://yunus.hacettepe.edu.tr/ tonta/courses/spring2009/bby606/SPSS_15.0_ile_Veri_Analizi.p df [12.09.2012].

[42] Turgut, Mf. (1977), Measurement and Evaluation in Education, Ankara: Nuve Press.

\section{Authors}

Omer Karaman, Ordu University, Faculty Education, Department of Educational Sciences, Psychological Counseling and Guidance, Turkey. E-mail: okaraman44@hotmail.com

Yuksel Cirak, Inönü University, Faculty Education, Department of Educational Sciences, Psychological Counseling and Guidance, Turkey. E-mail: yuksel.cirak@inonu.edu.tr 